\title{
Study on the Improvement of College Students' Spare Time Management Ability in Sichuan University of Arts and Sciences
}

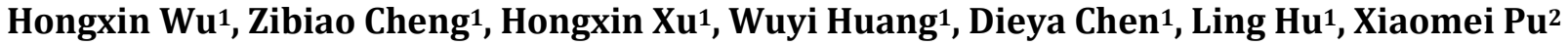 \\ ${ }^{1}$ School of Finance and Economics Management, Sichuan University of Arts and Science, Dazhou, China \\ ${ }^{2}$ Research Center of Sichuan Old Revolutionary Areas Development, Sichuan University of Arts and Science, Dazhou, China \\ Email:2199382311@qq.com
}

How to cite this paper: $\mathrm{Wu}, \mathrm{H}$. X., Cheng, Z. B., Xu, H. X., Xu, H. X., Huang, W. Y., Chen, D. Y., Hu, L., \& Pu, X. M. (2020). Study on the Improvement of College Students' Spare Time Management Ability in Sichuan University of Arts and Sciences. Voice of the Publisher, 6, 140-149. https://doi.org/10.4236/vp.2020.63016

Received: September 2, 2020

Accepted: September 26, 2020

Published: September 29, 2020

Copyright $\odot 2020$ by author(s) and Scientific Research Publishing Inc. This work is licensed under the Creative Commons Attribution International License (CC BY 4.0).

http://creativecommons.org/licenses/by/4.0/

\begin{abstract}
On the basis of defining their spare time, investigation was carried out on the situation of college undergraduates' spare time management in Sichuan University of Arts and Sciences. This paper analyzes the length of spare time, the cognition of the spare time, the specific utilization using and arrangement of the extracurricular time, and the utilization of the Internet and learning, etc., and then puts forward the strategies to improve the students' spare time management ability of Sichuan University of Arts and Sciences: from the school point of view, it is suggested that we should educate and guide students to establish correct values of spare time management, set up spare time management courses or lectures, carry out time management training and hold characteristic activities to enrich the spare life of college students. From the perspective of students, it is suggested that the importance of spare time should be clarified, attention should be paid, reasonable time planning should be made, quality of spare life should be improved, good living habits should be formed, and scientific work and rest time should be followed.
\end{abstract}

\section{Keywords}

College Students, Spare Time Management Ability, Sichuan University of Arts and Sciences

\section{Introduction}

In the university stage, under the influence of school teaching form and talent training mode, college students have more free spare time than primary and middle school students. It is a valuable treasure for college students, which cannot be ignored and wasted. If college students can manage their spare time well, 
it can not only promote their professional accomplishment, but also cultivate their application-oriented compound ability. However, not every college student can arrange his/her spare time in a scientific and reasonable way. Therefore, it is important and of practical significance to strengthen the research on the improvement of college students' spare time management ability.

\section{Definition of Spare Time}

Through the database of Cnki, this paper searched college students' spare time management as the key words, and found that there are 64 articles in the relevant journals that study college students' spare time management, among which Hui Li believes that college students' spare time refers to the life style and life content reflected in students' free time beyond the prescribed learning time (Li, 2016). According to Feixia $\mathrm{Hu}$, it refers to the time outside the classroom for college students, which is left at their disposal after deducting the necessary time for sleeping, eating and repeating life $(\mathrm{Hu}, 2017)$. Hongli Zhang pointed out that it is the time left over from classes, experiments, internships and other courses arranged by the school education and teaching plan. It is the time for students to independently allocate time to complete homework, experiments, review, self-study and entertainment (Zhang, 2018).

When scholars define the spare time, they all think that the spare time is the disposable time outside the teaching arrangement, and a few scholars deduct the rest time and the necessary time for maintaining life. The author thinks that the rest time and the necessary time to maintain life seem to be controllable, but in fact the time to complete certain actions is not easy to be controlled.

Accordingly, this paper holds that spare time refers to the disposable time after deducting the university teaching arrangement, rest and necessary time to maintain life, which specifically includes the disposable time of listening to lectures after class, reviewing after class, doing scientific research projects, developing self-interests and entertainment.

\section{Investigation on the Management of College Students' Spare Time in Sichuan University of Arts and Sciences}

Sichuan University of Arts and Sciences, located in Dazhou city, Sichuan Province, has been holding higher education since 1976, known as Da County Normal College. In February 2006, it was approved to be an undergraduate university, and is the only ordinary undergraduate university in eastern Sichuan.

The university now has two campuses, Lianhu and Nanba, with more than 20,000 students (including continui, ng education students and international students). Full-time education recruits students from 22 provinces and cities, including Sichuan, Ningxia, Inner Mongolia, Gansu, Jiangxi, Hunan, Fujian, Anhui, Hubei, Henan, Hebei and other provinces and cities, among which Sichuan students accounted for the majority. (From the official website of Sichuan University of Arts and Sciences) 
In order to avoid the singularity and limitation of the survey results, ensure the completeness and rationality of the survey results, and reduce the errors of the survey results, the respondents were college students of all grades in Sichuan University of Arts and Science. Questionnaires were distributed online on December 17, 2019 (https://www.wenjuan.com/s/EniEfq/?Share_device=weixin) and by January 3, 2020, a total of 443 valid questionnaires have been collected. The questionnaire results are summarized and analyzed as follows.

\subsection{Sex Ratio}

As shown in Table 1, among the 443 randomly selected questionnaires, there were 215 male students and 228 female students, with a male and female ratio of $49 \%$ and $51 \%$ respectively, which were roughly equal, effectively ensuring the rationality of the survey results (Tang, 2010).

\subsection{Grade Distribution}

As shown in Table 2, among the 443 randomly selected questionnaires, there were 115 freshmen, 123 sophomores, 150 juniors and 55 seniors, accounting for $26 \%, 28 \%, 34 \%$ and $12 \%$ respectively. In the senior year, due to the situation of off-campus internship, civil service examination and postgraduate entrance examination, there are few data collected. Meanwhile, the purpose of this research is mainly to point out problems and provide suggestions for the use of spare time in the first, second and third years.

\subsection{The Length of Spare Time}

As shown in Table 3, there are 54 students with less than 10 hours of spare time, accounting for $12 \%, 172$ students with 10 to 20 hours of spare time, 126 students with 20 to 30 hours of spare time, accounting for $28 \%$ and $39 \%$, and 91 students

Table 1. Gender distribution.

\begin{tabular}{ccc}
\hline gender & subtotal (person) & percentage (\%) \\
\hline male & 215 & 49 \\
female & 228 & 51 \\
total & 443 & 100 \\
\hline
\end{tabular}

Table 2. Grade distribution.

\begin{tabular}{ccc}
\hline grade & subtotal (person) & percentage (\%) \\
\hline freshmen & 115 & 26 \\
sophomores & 123 & 28 \\
juniors & 150 & 34 \\
seniors & 55 & 12 \\
total & 443 & 100 \\
\hline
\end{tabular}


with more than 30 hours of spare time, accounting for $21 \%$. According to the above data, college students' spare time from Monday to Friday is mainly between 10 to 20 hours and 20 to 30 hours, and $12 \%$ of them have less than 10 hours. The subjects' spare time is generally adequate.

\subsection{The Cognition of Spare Time}

As shown in Figure 1, college students who participated in the questionnaire basically believe that making good use of their spare time can bring a lot of benefits, such as $24 \%$ of college students think that making good use of their spare time helps to form a habit of self-discipline; $20 \%$ of college students also think that making good use of their spare time will help them finish their study plan on time and in addition, $21 \%$ of college students think that making good use of their spare time is conducive to cultivating personal hobbies and so on, etc.. Only the specific gravity data are listed here, although college students know that making good use of their spare time will bring many benefits.

As shown in Table 5, college students who participated in the questionnaire made plans for their spare time, and 54 indicated that they could carry them out as planned, accounting for $12 \%, 181$ could complete on schedule in general, accounting for $41 \%, 146$ and 62 students who can't and have never finished, respectively, accounting for $33 \%$ and $14 \%$, indicating that nearly half of the college students can't finish the plan in their spare time and their execution is poor.

Table 3. The situation of remaining spare time from Monday to Friday.

\begin{tabular}{ccc}
\hline spare time from Mon. to Fri. & subtotal (person) & percentage (\%) \\
\hline less than 10 hours & 54 & 12 \\
10 to 20 hours & 172 & 28 \\
20 to 30 hours & 126 & 21 \\
more than 30 hours & 91 & 100 \\
total & 443 &
\end{tabular}

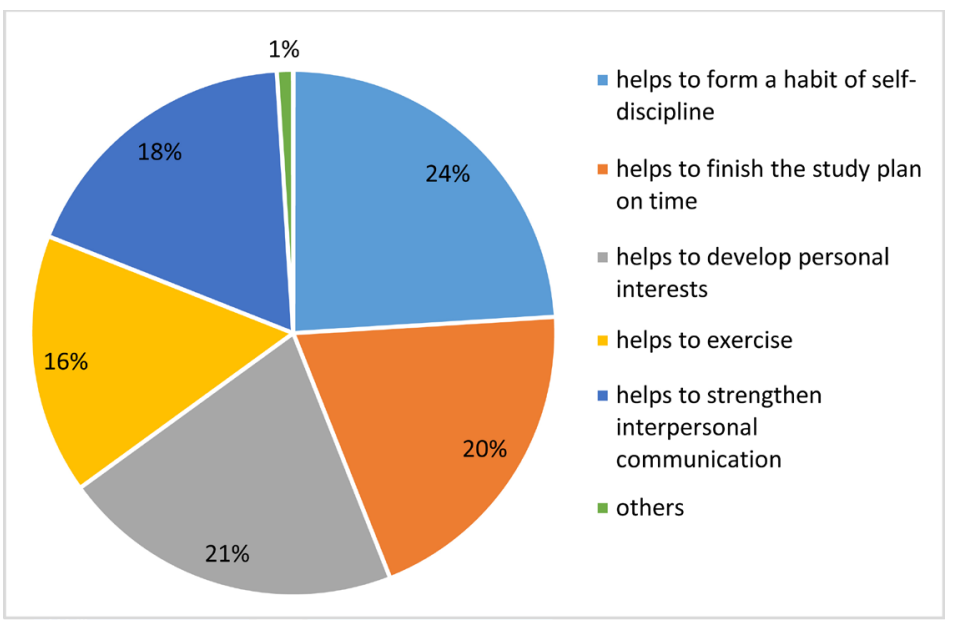

Figure 1. The meaning of making good use of spare time. 


\subsection{Management of Spare Time}

\subsubsection{The Arrangement and Implementation of Spare Time Plan}

As shown in Table 4, survey respondents generally make plans in their spare time, which can be divided into: thinking only, making written plans and never making plans, respectively 279 people, 63\%, 51 people, $12 \%$ and 113 people, $25 \%$. It can be seen from this set of data that the former two situations account for a large proportion, which indicates that most students do not have the habit of making specific written plans and arrangements for their spare time.

As shown in Table 5, only $12 \%$ of the students could complete the spare schedule according to the plan, $41 \%$ generally completed the schedule, and the rest finished poorly. According to the survey results, nearly half of the students are not optimistic about the completion and have poor execution. Only a small number of students can complete their own schedule.

\subsubsection{The Use of Spare Time}

\section{1) Overall utilization of spare time}

As shown in Figure 2, most of the surveyed college students spend their spare time surfing the Internet, then studying and participating in club activities, and finally doing part-time jobs, doing physical exercises and spending time with boyfriends or girlfriends. It can be seen from the figure that the overall use quality of college students' spare time is not high and relatively simple.

\section{2) The situation of Internet use in spare time}

As shown in Figure 3, samples corresponding to the college students use their spare time for Internet: $10 \%$ for 5 hours, $24 \%$ between 5 to 10 hours, 10 to 20 hours between $38 \%$ and $28 \%$ for more than 20 hours, of which $66 \%$ college students spend their spare time surfing the Internet for more than 10 hours, only $34 \%$ of college students spend their spare time surfing the Internet within 10

Table 4. The arrangement of spare time.

\begin{tabular}{ccc}
\hline planning situation & subtotal (person) & percentage (\%) \\
\hline thinking only & 279 & 63 \\
making written plans & 51 & 12 \\
never making plans & 113 & 25 \\
total & 443 & 100 \\
\hline
\end{tabular}

Table 5. Completion of the plan for spare time.

\begin{tabular}{ccc}
\hline condition of execution of plan & subtotal (person) & percentage (\%) \\
\hline could complete & 54 & 12 \\
generally complete & 181 & 41 \\
usually not & 146 & 33 \\
never done & 62 & 14 \\
total & 443 & 100 \\
\hline
\end{tabular}


hours. As shown in Figure 3, most of their spare time is spent on playing games, chatting and reading novels, followed by studying and searching materials.

\section{3) Learning situation in spare time}

As shown in Table 6, spending less than 5 hours on study accounts for $26 \%$, spending between 5 and 10 hours on study accounts for $38 \%$, spending between 10 and 20 hours on study accounts for $22 \%$, and spending more than 20 hours on study accounts for $14 \%$. It can be seen that using spare time to study for 5 to

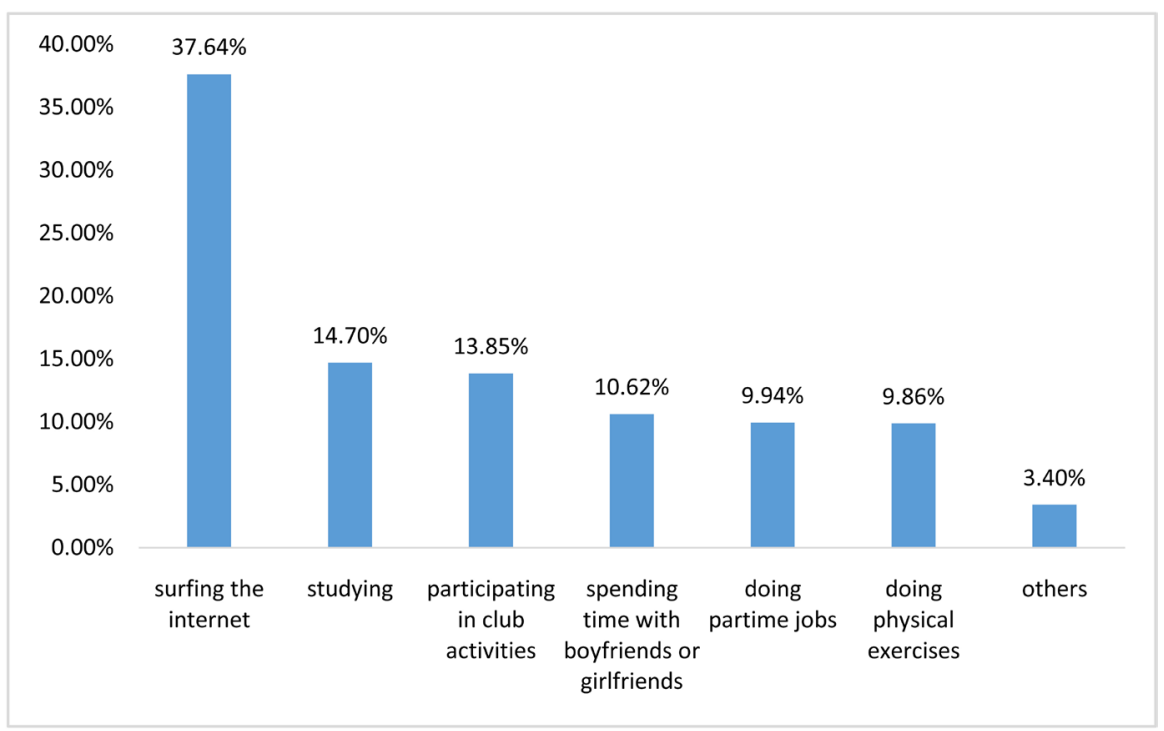

Figure 2. The arrangement of college students' spare time.

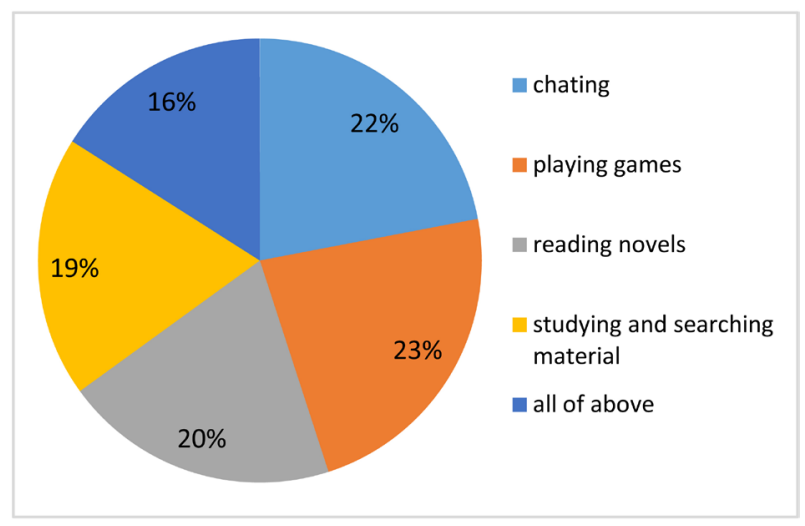

Figure 3. The situation of taking up spare time on the Internet.

Table 6. The situation of spare time on study of a week.

\begin{tabular}{ccc}
\hline spare time spent on study & subtotal (person) & percentage (\%) \\
\hline less than 5 hours & 115 & 26 \\
5 and 10 hours & 171 & 38 \\
between 10 and 20 hours & 96 & 22 \\
more than 20 hours & 61 & 14 \\
total & 443 & 100 \\
\hline
\end{tabular}


Table 7. Main factors affecting the management of spare time.

\begin{tabular}{ccc}
\hline affecting factors & subtotal (person) & percentage (\%) \\
\hline school activities & 245 & 39 \\
personal affairs & 290 & 46 \\
family affairs & 85 & 13 \\
others & 16 & 2 \\
total & 443 & 100 \\
\hline
\end{tabular}

10 hours accounts for a large proportion.

\section{4) Factors influencing the management of spare time}

As shown in Table 7, it can be seen that the main factors affecting the spare time are school activities and personal affairs, accounting for 39\% and $46 \%$ respectively. It can be seen that college students' spare time is mainly in these two aspects, while family affairs and other matters account for only $15 \%$.

\section{Strategies for Improving College Students' Ability to Manage Their Spare Time in Sichuan University of Arts and Sciences}

How to make college students attach importance to their spare time cannot be accomplished overnight. There are two main reasons: one is that some students have an inherent idea-after three years of hard study in high school, one can play more easily when one goes to college; the second is when people find that they can't play all the time in college, they don't know how to make good use of their spare time, but become confused and at a loss, so they have the mentality of "the broken pot is broken". Simply put it, it is the result of the interaction between external factors (mainly schools) and internal factors (mainly individuals) (Huang, 2011). Based on this, this paper puts forward strategies to improve college students' spare time management ability in Sichuan University of Arts and Sciences from school and individual levels (Bi, 2013).

\subsection{School Level}

\subsubsection{Educate and Guide the Students to Establish the Correct Values of Spare Time Management}

Time is non-renewable. Schools should educate and guide college students to establish correct values of spare time management in both theory and practice during the education process. In theory, college students can realize the importance of their spare time from the ideological perspective, guide and cultivate them in the practice process, create a good time management atmosphere, let students experience the benefits of effective use of time, and strive to give full play to the maximum effect of their spare time. For example, it can be guided through weekly class meetings, theme groups and other ways.

\subsubsection{Offer Lectures on Relevant Courses and Conduct Time Management Training}

On the basis of cultivating the values of college students' correct spare time 
management, the school can provide systematic and clear guidance and training for the improvement of college students' time management ability by offering special lecture courses. The survey shows that most college students are aware of the positive significance of making good use of their spare time, but in the process of practice, due to their lack of scientific management skills, the effect is not good. According to the actual situation of college students, theoretical knowledge and practical skills of time management should be taught to improve their ability of time management. Sichuan University of Arts and Sciences currently offers courses on career planning, but there is no specialized course on time management. Based on this, time management courses can be set up in schools.

\subsubsection{Hold Characteristic Activities to Enrich College Students' Spare Life}

Generally speaking, there are many extracurricular activities in colleges and universities. However, some activities are mandatory, so students are hardly interested in them and struggle to cope with them. As time goes by, they will get tired of participating in activities and stay in dormitories. According to the actual situation of students, schools can carry out distinctive activities that can attract students to participate in, and guide students to make healthy use of their spare time. For example, outdoor activities such as night running and walking can be held to encourage and attract more students to participate through the reward and punishment mechanism of quantitative comprehensive test points.

\subsection{Individual Level}

\subsubsection{Define the Importance of Spare Time and Improve the Degree of Self-Importance}

The thought is the forerunner of the action, to carry on the effective management to the spare time, first must realize the importance from the thought. College students are those who dominate and enjoy their spare time. If they can use their spare time properly, they can improve their learning ability and enrich their life, so that they can achieve all-round development in all aspects. Understand the importance of spare time and the positive significance of proper use from the perspective of cognition, and improve the importance of their own (Ye, 2013).

\subsubsection{Make a Reasonable Time Plan to Improve the Life Quality of Spare Time}

The first step in thinking about the importance of your spare time is to take action. First of all, we should make a reasonable time plan and comprehensively consider our own situation, such as major, extracurricular time, life goal, career planning, interests and hobbies, etc., so as not to blindly follow the crowd and be impractical. As college students receiving higher education, they should not only spend their spare time on low-quality activities such as playing games, shopping and falling in love, but also actively participate in student activities, cultivate 
personal interests and other active and healthy lifestyles to improve the quality of spare life.

\subsubsection{Develop Good Living Habits and Follow a Scientific Schedule}

Self-management necessarily involves the management of habits and habits. Nowadays college students waste a lot of time because of their bad living habits. If the bad habits can't be changed, the problem of using spare time cannot be a good solution. The cultivation of good living habits must include following the scientific work and rest time. The body is the capital of the revolution and black and white life is easy to make people sleepy, not focused, anxious, memory decline, which are very detrimental to the management of spare time (Zhang, 2013).

\section{Conclusion}

How college students use their spare time and through what kinds of ways and activities to full and enrich their spare time life reflect their attitude towards life and even affect their future life and work. Not only should one use these hours to consolidate the knowledge one has learned in class, but one should also use their spare time to increase their knowledge as well as improve their professional level and comprehensive quality. Therefore, every college student should plan his/her time reasonably to improve the planning and managing ability of his/her spare time.

\section{Funded Project}

The research results of 2019 Undergraduate Scientific Research Project of Sichuan University of Arts and Sciences (Project Number: X2019R096).

\section{Conflicts of Interest}

The authors declare no conflicts of interest regarding the publication of this paper.

\section{References}

Bi, R. (2013). Study on the Present Situation and Countermeasures of Cultivating College Students' Management Ability on Spare Time. Research and Practice on Higher Education, 32, 69-72.

Hu, F. X. (2017). Investigation and Analysis of College Students' Use of Spare Time-A Case Study of Anhui University. Statistics and Management, No. 8, 27-28.

Huang, X. Y. (2011). Problems and Countermeasures of College Students' Spare Time Management. Journal of Chongqing University of Science and Technology (Social Sciences Edition), No. 11, 183-184.

Li, H. (2016). The Present Situation and Countermeasures of College Students' Use of Spare Time. Journal of Hubei Adult Education Institute, 22, 72-75.

Tang, J. (2010). Investigation and Analysis of College Students' Spare Time Management. China Journal of Health Psychology, 18, 1101-1102. 
Ye, G. P. (2013). Study on Time Management of College Students. Journal of Hubei University of Economics: Humanities and Social Sciences, 10, 140-141.

Zhang, H. L. (2018). Countermeasures on Effective Use of College Students' Spare Time under the New Media Environment. Teaching and Educating (Higher Education Forum), No. 36, 12-13.

Zhang, P. (2013). An Investigation and Analysis on the Management of College Students' Spare Time. Success (Education), No. 20, 168-169. 